\title{
Two Perspectives On Botsourcing And Employment
}

\author{
Richard Vedder, University of North Texas, USA \\ Carl S. Guynes, University of North Texas, USA \\ James Parrish, University of North Texas, USA
}

\begin{abstract}
Botsourcing is the augmentation or replacement of human jobs by robots or other computing systems. Despite its growing popularity, much uncertainty and even fear exists about its use. This paper summarizes considerations expressed by both sides of this issue.
\end{abstract}

Keywords: Botsourcing; IT Workers; Man-Machine Systems; Unemployment; Retraining

\section{INTRODUCTION}

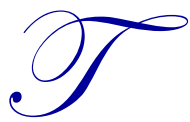

here are serious concerns that robotics and AI systems are going to replace a great many human jobs. A study at Oxford in 2013 stated that "about 47 percent of total U.S. employment" could be vulnerable over the next few decades (Frey \& Osborne, 2013). A McKinsey Global Institute report made similar conclusions (Manyika et al. 2013). Both studies believe that jobs involving physical work in well-structured, predictable tasks, as well as jobs requiring data collection and analysis, are at greatest risk of being "botsourced." In their book The Second Machine Age, Brynjolfssson and McAfee (2014) have observed that "there's never been a worse time to be a worker with only 'ordinary' skills and abilities to offer, because computers, robots, and other digital technologies are acquiring these skills and abilities at an extraordinary rate."

\section{A NEGATIVE VIEWPOINT}

The history of oil production in west Texas, particularly the Permian Basin area, can be summarized in the phrase "boom or bust." Rising prices accelerate drilling and hiring. Declining prices witness scant drilling and massive layoffs. With little in the way of economic diversification, in bad times the entire region tries to hibernate. The unemployed either leave or try to endure until good times return. Since prices last peaked in 2014, Texas has lost about 98,000 oil jobs, $60 \%$ of the national total (Krauss, 2017). Now, oil prices are starting to recover. The hiring has not.

Demand for greater efficiency and cost savings is pushing the Permian Basin drillers to adopt robotics and computer systems augmented by AI (expert systems, neural networks, data miners, and the like). Before this latest automation, a small producer in west Texas might employ 35 workers per land drilling rig; a large producer might have as many as 55 direct personnel per rig (Anon, 2017). Today's semi-automated rigs employ half that number (Chase, 2017). This replacement of human workers by robots and automated technologies is called botsourcing. The experience of the Permian Basin oil workers is just one example of how botsourcing is changing the workplace environment both here and abroad (UK-RAS Network, 2016).

Advances in technology have often caused job loss. Consider, for example, how digital cameras brought low the film giant Eastman Kodak, streaming video closed Blockbuster, and the growth of online shopping helped bankrupt Toys R Us. Yet automation does not move through an economy like a tidal wave or a speeding locomotive. Historically, it has happened in fits and spurts. Most organizations do not see themselves technologically as leading-edge, not to mention "bleeding-edge," when it comes to innovation. And botsourcing faces serious constraints. 
One brake is the matter of perceived trust. Certainly, there is the age-old question in an updated guise: Will the new robot or AI-augmented system perform as well, and at least as reliably, as a human employee? This question is especially relevant in those industries where the technologies are nascent, such as autonomous vehicles where a woman an autonomous vehicle struck and killed in the United States that had a human backup behind the wheel. However, it is also important not to forget the 'customer' - the recipient or beneficiary of the activity performed by the robot or AI system. Will this customer trust the new technology? Or will the customer perceive poorer service / response / interaction when compared with a human? The nature of the task being automated may significantly impact level of trust. Waytz and Norton (2014) report that their experiments have revealed a "psychology of botsourcing." Study participants reported that they were more at ease with computer systems assuming tasks demanding a high level of processing and analysis ("cognition") than tasks requiring creativity and feeling ("emotion").

Concerns about legal liability are another brake. For example, could an organization be threatened with legal action for using a robot or AI-augmented computer system? Conversely, could the organization be legally vulnerable if such technologies existed but were not used by the firm? Again, suppose a robot or AI-augmented system malfunctions. Who is responsible: the developer, the owner, or the operator? Until a body of case law develops for these situations, lawyers will rely on past cases for which they can successfully argue relevance by analogy. One such instance is the T.J. Hooper case from 1932 (60 F.2d 737, 1932). The plaintiff sued the operator of the T.J. Hooper and associated tugboats for the loss in a storm of two barges loaded with coal. The plaintiff argued that the operator was guilty of negligence because, had his boats been equipped with radios, their captains would have known about the approaching storm and could have diverted to a safe harbor. The defendant argued that there was no law requiring the use of radios on tugboats at the time of the accident. The court ruled for the plaintiff, observing that the technology (i.e., an AM radio set) was (a) readily available for purchase (in many stores in the U.S.); (b) priced reasonably (demonstrated by sales data); and (c) considered highly reliable (shown by advertising revenue and the Federal Government's use of AM radio to provide weather alerts to the public).

Insurance rates, in part set by liability concerns, can act as a third brake. Predictability is one foundation of the insurance business, and new technologies have little track record for adjusters to rely on. In some instances, legislative action can help reduce uncertainty. For example, 33 states have either enacted or are considering laws regulating the use of autonomous vehicles (Essex \& DuBois, n.d.).

In sum, most organizations will wait for others in their industry to take the plunge - and have successful results before venturing into botsourcing waters.

\section{A POSITIVE VIEWPOINT}

When Boxed, a New Jersey company, introduced product-retrieval robots to their fulfillment-center warehouse, more than 100 employees feared for their jobs. But their concerns proved unfounded: not a single person was laid off. Warehouse employees discovered that they liked their jobs better with the robots helping. Their jobs were made easier because the robots did more of the physically taxing work. The workers were able to stay at their workplace, and let the robotic system bring items to them, which drastically reduced the amount of walking that they were required to do. Further, Boxed retrained the product-retrieval employees to operate and maintain the robots, or transitioned them to other needs within the company. The most surprising result was that the improved productivity and service led to so much new business that Boxed had to recruit another shift to handle the increased demand (Chase, 2017).

The experience that the Boxed company saw occur has also happened to a number of other companies, particularly those e-commerce organizations that use robotics to improve delivery times thru automated selection of merchandise for shipment. In many of these instances, more jobs have been created than eliminated thru the use of robotics and automation. The e-commerce industry has had to build a large network of delivery and warehouse systems utilizing humans and robots. A very positive thing has occurred in that many of the jobs performed by robots never existed prior to the automation.

Who could have predicted twenty years ago that there would be demand today for workers to manage a company's or even a person's - web (social media) presence? Just because we cannot foresee many of the future jobs does not mean that those jobs will not exist. Moreover, during the early Industrial Revolution in Britain there was a delay 
between craft-worker layoffs and the creation of the new industrial jobs that employed a growing labor force. We may be witnessing a similar phenomenon today. Nevertheless, it is possible to make some general observations about future employment opportunities.

First, whenever a new automation technology enters the marketplace, someone must perform each of the following activities:
1. Design
2. Build
3. Program
4. Test
5. Deliver
6. Install
7. Train
8. Use
9. Manage
10. Maintain
11. Update
12. Replace
13. Dispose/recycle

For a given application, computerization may be able to perform some parts of these activities, but probably not all of them, thus requiring skilled human workers.

Second, relatively few jobs are completely automatable. Instead, most occupations have a structured component that could be computerized, while the remaining, unstructured part must be performed by a human. This suggests that many future jobs will require human-AI machine collaboration. For example, imagine one or more robots processing and analyzing a crime scene while human detectives focus on interviews and the actual investigation. Interestingly, the employability of those humans having the skills to perform the non-automatable tasks should rise.

Lastly, as computerization proceeds, successful companies will shift employee responsibilities increasingly to unstructured activities, such as building and maintaining person-to-person relationships with customers, suppliers, and other groups. Relationship management will continue to be an important way for a company to distinguish itself from competitors.

\section{CONCLUSION}

The net impact of the latest round of automation on the total workforce is still unclear (Price Waterhouse Coopers, 2017). Part of this uncertainty comes from the risks associated with introducing new technologies. However, botsourcing is now replacing some forms of traditional employment, and will continue to do so for the foreseeable future. The challenge for organizations will be identifying the most cost-effective applications for botsourcing, or for a human-machine hybridization. The challenge for societies will be creating practical ways for displaced workers to acquire the new job skills needed for future prosperity.

\section{AUTHOR BIOGRAPHIES}

Richard G. Vedder is a Professor of Information Systems at the University of North Texas. He received his Ph.D. from the University of Arizona. His research interests include multimedia systems, knowledge-based systems, impact of new technologies and competitive intelligence. He has published articles in Decision Sciences, Communications of the ACM, Computers and Society, IEEE Transactions on Systems, Man and Cybernetics, Expert Systems, and Journal of Information Systems Management. (Contact Author) Email: vedder@unt.edu

Carl S. Guynes is a Regents Professor of Information Systems at the University of North Texas. He received a doctorate in quantitative analysis from Texas Tech University. Dr. Guynes' areas of specialization are client/server computing, end-user computing, data administration, and information resource management. His most recent research efforts have been directed in the areas of client/server computing and data administration. Some of the journals in which Dr. Guynes has published include Communications of the ACM, Information \& Management, The Journal of Information Systems Management, Journal of Accountancy, Journal of Systems Management, The Journal of Database Management, The CPA Journal, The Journal of Computer Information Systems, Information Strategy, Computers and Security, and Computers and Society. 
James Parrish is an Assistant Professor of Information Systems at the University of North Texas. He received his $\mathrm{Ph}$. D. from the University of Central Florida. His research interests include knowledge management systems, design science, and socio-technical security issues in social networking. He has published journal articles in Communications of the ACM, Journal of Information Systems Education, Information Systems Management, Communications of the AIS, and Ethics and Information Technology.

\section{REFERENCES}

Anon. (2017). How many jobs are associated with each U.S. land rig? Retrieved from http://oilpro.com/q/1748/many-jobsassociated-each-us-land-rig

The T. J. Hooper, 60 F.2d 737, 1932 U.S. App. LEXIS 2592 (2d Cir. N.Y. July 21, 1932). Retreived from http://www.casebriefs.com/blog/law/torts/torts-keyed-to-epstein/the-negligence-issue/the-t-j-hooper-3/.

Chase, R.E. (2017). Automation transforming the oil and gas industry. Marietta Times.

Frey, C. \& Osborne, M. (2013). The future of employment: How susceptible are jobs to computerisation? Oxford Martin School working paper.

Krauss, C. (2017). Oil recovers, but not its jobs. The New York Times.

Manyika, J., Chui, M., Bughin, J., Dobbs, R., Bisson, P. \& Marrs, A. (2013). Disruptive technologies: Advances that will transform life, business, and the global economy. McKinsey Global Institute Report.

Essex, A., \& DuBois, G. (n.d.). Retrieved from http://www.ncsl.org/research/transportation/autonomous-vehicles-legislativedatabase.aspx

Price Waterhouse Coopers. (2017). Will Robots Steal our Jobs? Section 4 in 2017 UK Economic Outlook, PWC White Paper.

UK-RAS Network. (2016). Manufacturing Robotics: The Next Robotic Industrial Revolution. UK-RAS White Paper. 1.

Waytz, A. \& Norton, M. (2014). Botsourcing and outsourcing: robot, British, Chinese, and German workers are for thinking - not feeling - jobs. Emotion, 14(2), 434-444. 